\title{
RANCANG BANGUN MESIN ROLL BENDING PORTABLE
}

\author{
Yusuf Eko Nurcahyo ${ }^{1}$, Mario Sariski Dwi Ellianto ${ }^{2}$
}

\author{
Teknik Manufaktur \\ Politeknik 17 Agustus 1945 Surabaya, Indonesia \\ e-mail: 1yusufekonurcahyo@gmail.com, ${ }^{2}$ mariosde6@gmail.com
}

Diterima: 15 September 2018. Disetujui : 5 Desember 2018. Dipublikasikan : 10 Desember 2018

(C)2018 -TESJ Fakultas Teknik Universitas Maarif Hasyim Latif. Ini adalah artikel dengan

akses terbuka di bawah lisensi CC BY 4.0 (https://creativecommons.org/licenses/by/4.0/)

\begin{abstract}
ABSTRAK
Revolusi Industri 4.0 menuntut Industri kecil bidang perbengkelan dalam peningkatan kualitas sumber daya manusia dan teknologinya dengan penggunaan mesin-mesin canggih pada proses produksi yang bertujuan meningkatkan efisiensi dan efektifitas produksi. Pada kenyataannya, sebagian besar IMKM perbengkelan saat ini masih menggunakan teknologi konvensional dan sederhana dalam menghadapi perkembangan Revolusi Industri 4.0. Maka perlu dilakukan upgrading teknologi agar IMKM bisa bersaing. Salah satu contoh proses produksinya yaitu proses bending yang dilakukan secara manual, sehingga hasil produk kurang memenuhi standar yang diinginkan baik secara kualitas dan waktu proses yang relatif cukup lama. Untuk mengatasi permasalahan tersebut, maka diperlukan inovasi pada proses bending tersebut dengan menggunakan mesin roll bending portable yang memakai penggerak mesin bubut atau jenis mesin motor penggerak lainnya. Dengan penggunaan mesin roll bending portable tersebut, diharapkan IMKM perbengkelan mampu bertahan dan menghadapi Revolusi Industri 4.0 melalui proses produksi semi otomatis. Dari hasil penelitian didapatkan mesin roll bending portable dengan spesifikasi dimensi; $350 \times 250 \times 560 \mathrm{~mm}$; penggerak utama yaitu mesin bubut dengan bantuan cross joint; mekanisme penekan : tuas ulir linier; sistem transmisi : gear box reducer 1:60, 2 buah gear sprocket rs 40 (36:36), rantai rs 40. Berdasarkan hasil uji coba mesin didapatkan proses pengerolan pipa galvanis diameter 1 inch dengan panjang mula-mula $580 \mathrm{~mm}$ dengan hasil radius $195 \mathrm{~mm}$ dengan waktu 20 menit dan pipa galvanis diameter 1 inch dengan panjang mula-mula $1200 \mathrm{~mm}$ dengan hasil radius $980 \mathrm{~mm}$ dengan waktu 30 menit.
\end{abstract}

Kata kunci: imkm, mesin bending

\section{PENDAHULUAN}

Perkembangan industri manufaktur utamanya industri perbengkelan manufaktur semakin berkembang dengan pesat dan cepat berdasarkan data BPS tahun 2017 industri manufaktur naik sebesar $4.74 \%$ terhadap tahun 2016. Dengan kenaikan industri manufaktur bisa menjadikan peluang atau ancaman dengan adanya Revolusi Industri 4.0 utamanya manufaktur di bidang perbengkelan.

Untuk memenuhi Penerapan Revolusi Industri 4.0 agar bisa bersaing IMKM perbengkelan dibutuhkan sumber daya manusia yang berkualitas tinggi dalam menyeimbangkan kemajuan teknologi yang ada. Seseorang harus memiliki suatu keahlian di bidang tertentu agar dapat ditempatkan pada bidang yang tepat guna memenuhi kebutuhan di industri itu sendiri. Selain dari segi sumber daya manusiannya, tidak kalah penting juga harus diperhatikan dari segi teknologi penunjangnya. Industri menggunakan mesin-mesin canggih untuk melakukan proses produksi, hal ini bertujuan untuk meningkatkan efisiensi dan efektifitas produksi.

Hampir semua IMKM perbengkelan saat ini masih menggunakan teknologi yang bisa di bilang jadul atau kadaluarsa untuk menghadapi perkembangan Revolusi Industri 4.0 sehingga perlu upgrade teknologi agar IMKM tersebut tidak gulung tikar. Ini bisa dilihat dari proses bending yang dilakukan secara manual, sehingga selain produk kurang maksimal hasilnya juga membutuhkan waktu yang lumayan lama pada proses bending tersebut.

Untuk mengatasi permasalahan tersebut kami menemukan sebuah inovasi untuk pembuatan mesin roll bending portable dengan penggerak mesin bubut atau mesin motor lainnya. Diharapkan mesin roll bending portable dapat mengatasi permasalahan yang terjadi pada IMKM perbengkelan dan bisa menghadapi Revolusi Industri 4.0 dengan mengganti proses bending manual menjadi otomatis.

Penelitian ini diharapkan mempunyai suatu manfaat bagi IMKM pebengkelan yaitu: 
1. Mesin roll bending portable ini mudah digunakan.

2. Mempercepat proses bending dan meningkatkan efisiensi dalam waktu produksi dalam proses pengerolan.

\section{METODE PENELITIAN}

\section{Tahapan Metode Rancang Bangun Mesin Roll bending}

Adapun langkah-langkah dalam pelaksanaan penelitian ini mengacu pada konsep perancangan Ulrich-Epinger yang telah dimodifikasi mengikuti flow chart metode perancangan pada Gambar 1.

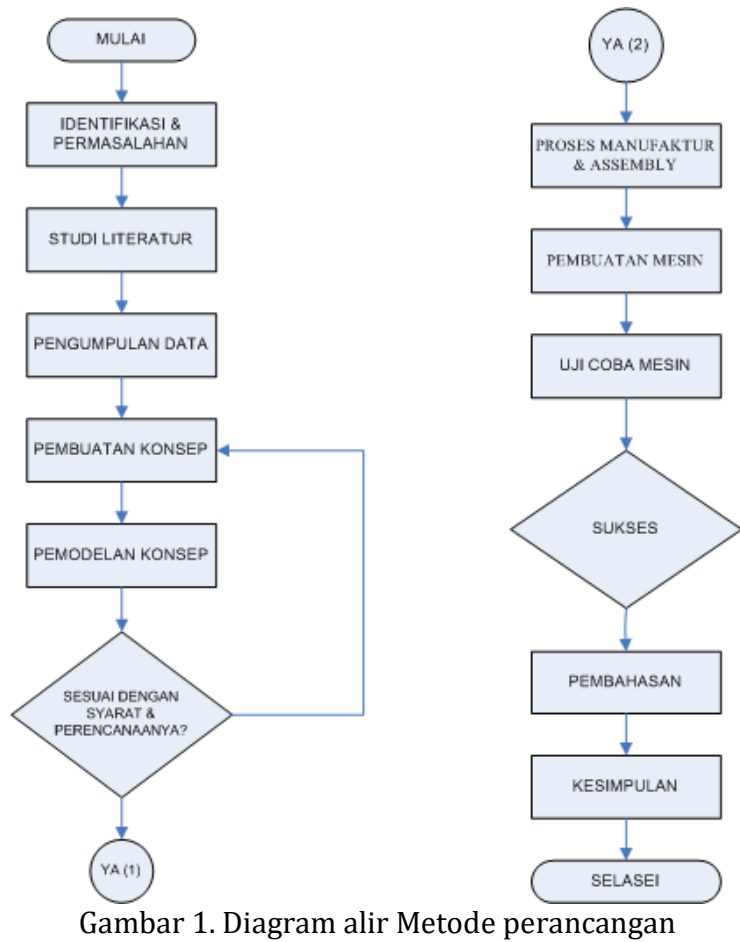

\section{Pembuatan Konsep}

Tahapan penting dalam sebuah awal pembuatan suatu produk. Dari data-data yang telah dikumpulkan dan dipelajari didapatkan sebuah konsep awal berdasarkan permasalahan yang ada serta penentuan spesifikasi produk beserta perhitungan-perhitungan yang diperlukan. Dalam pembuatan konsep yang baik yakni dengan mempertimbangkan variabel-variabel yang ada, sehingga akan didapatkan lebih dari satu konsep produk yang dihasilkan.

\section{Pemodelan Konsep}

Setelah didapatkan sebuah konsep terpilih, tahapan selanjutkan yakni mengubah konsep tersebuh kedalm sebuah model. Dalam hal ini biasanya digunakan software bantu yang dapat merepresentasikan konsep ke dalam bentuk nyata. Hal penting yang perlu diperhatikan setiap detail dari spesifikasi dari konsep yang terpilih.

\section{Pembuatan Detail Drawing}

Setelah memenuhi syarat perancangan berdasarkan analisis teknik, tahapan selanjutnya yaitu merubah 3D model kedalam bentuk 2D detail drawing atau lebih dikenal dengan gambar kerja. Detail drawing sendiri merepresentasikan rancangan dari design engineer. Sebuah ide dan gagasan tidak akan mempunyai arti apapun apabila tidak dituangkan ke dalam bentuk nyata. Begitu pula sebuah model, tidak akan bisa diwujudkan dalam bentuk nyata apabila tidak dirubah kedalam bentuk gambar detail yang dapat dipahami oleh para teknisi dan fabrikator. Oleh karena itu sebuah gambar detail yang baik diharapkan mampu mewakili seorang engineer untuk menjelaskan secara presisi ide-idenya kepada fabrikator.

\section{Proses Manufaktur dan Assembly}

Proses manufaktur dan assembly merupakan suatu kesatuan dimana pada proses manufaktur sendiri terjadi penambahan dan pengaplikasian bahan fisik maupun kimia untuk merubah bentuk geometri bahan atau produk. Pada tahap ini dilakukan berbagai proses-proses manufaktur, antara lain proses pembentukan, proses penyambungan, proses pemotongan dan proses perlakuan fisik. Selain terjadi proses manufaktur, tidak kalah pentingnya yaitu proses assembly, dimana proses ini menggabungkan antara beberapa part menjadi satu kesatuan produk jadi. Dalam proses ini assembly penting halnya untuk membaca gambar detail yang sudah dibuat, sehingga part-part dapat terhubung dengan baik dan benar.

\section{Pembuatan Mesin}

Pembuatan mesin merupakan tahapan lanjutan dan berkesinambungan dengan proses manufaktur dan assembly, pada tahap ini mesin roll bendingakan dibuat hingga tahap akhir atau barang jadi. Pada pembutan mesin ini ketelitian dan kepresisian sangat diperlukan agar mesin nantinya dapat bekerja dengan baik.

\section{Uji Coba Mesin}

Tahapan ini merupakan tahapan akhir dari perancangan dan pembuatan dari suatu mesin. Uji coba mesin sangat diperlukan untuk mencoba dan mengetahui performa dari mesin itu. Sebelum uji coba mesin diperlukan proses kalibrasi terlebih dahulu terhadap mesin untuk menambah kepresisian dan mengurangi eror yang akan terjadi nantinya.

\section{Pembahasan}

Setelah mesin jadi dan diuji coba sehingga sesuai dengan syarat yang diinginkan, maka tahapan selanjutnya adalah pembahasan. Dalam hal ini pembahasan dilakukan secara tertulis dan 

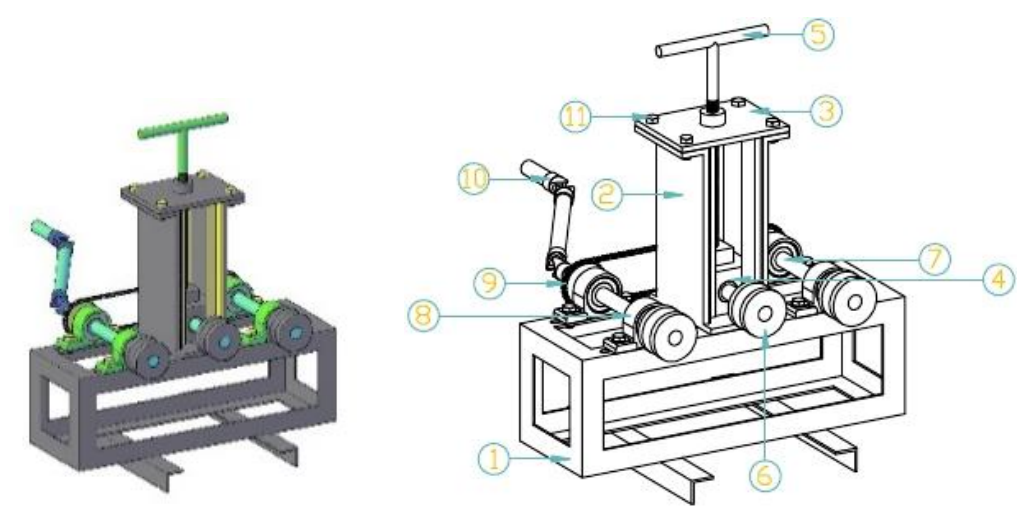

Gambar 2: Mesin roll bending

Keterangan :

1. Rangka meja

2. Rangka penyangga vertikal

3. Rangka penyangga horisontal

4. Rumah poros tengah

5. Tuas

6. Matras

7. Poros

8. Bearing

9. Rantai penggerak

10. Universal joint

11. Baut dan mur

berupa laporan penelitian sehingga dapat digunakan sebagaimana mestinya di kemudian hari.

\section{Kesimpulan}

Setelah mesin jadi dan telah di uji coba dengan baik, maka tahap selanjutnya merupakan pembuatan laporan mesin roll bending, dengan menarik kesimpulan yang dapat ditarik dari hasil pengujian yang telah dilakukan.

\section{HASIL DAN PEMBAHASAN}

\section{Gambaran Alat/Mesin Roll Bending}

Gambar 2 memperlihatkan desain dari mesin roll bending yang dibuat.

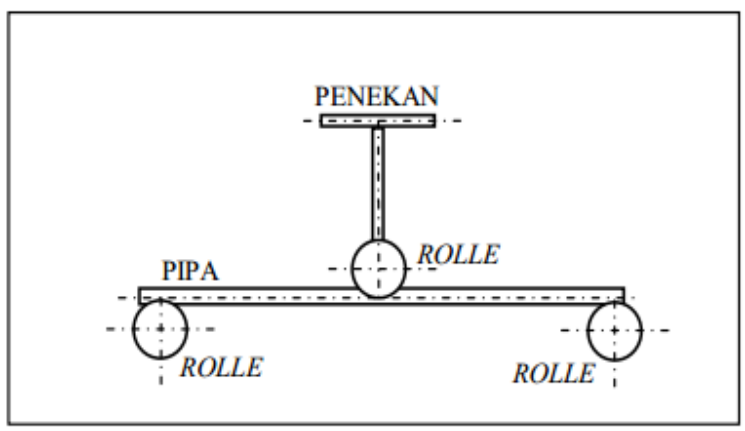

Gambar 3. Pengerolan pipa

\section{Teknik perancangan Alat/mesin roll bending Sistem pengerol pipa}

Alat/mesin pengerol pipa ini menggunakan tiga roller untuk system pengerolanya, dua roller sebagai landasan pipa sekaligus sebagi roller penggerak dan satu roller sebagai roller penekan. Sistem pengerolan dilakukan secara berulang ulang atau sedikit demi sedikit dalam proses pengerolanya, karena proses pengerolan tidak disertai dengan pemanasan.

Roller yang digunakan pada alat/mesin pengerol pipa ini direncanakan menggunakan bahan St37. Roller ini mempunyai ukuran $80 \mathrm{~mm} x$ $35 \mathrm{~mm}$ dengan ukuran profil yang sudah direncanakan. Roller diberi lubang tengah untuk penyambunganya dengan poros kemudian dikunci menggunakan baut sehingga sewaktu perawatan mudah dilepas atau jika ingin diganti dengan roller lain sesuai dengan keinginan.

- Analisa pipa yang akan digunakan

Pipa yang umumnya digunakan untuk pengerolan pembuatan properti biasanya adalah pipa galvanis, dikarenakan pipa galvanis mempunyai keuntungan nilai ekonomis yang cukup tinggi dan tahan karat atau korosi. Pipa galvanis pada dasarnya adalah pipa baja yang dilapisi galvanizing menggunakan cairan seng untuk melapisi baja. Untuk pengerolan ini dipilih pipa galvanis sebagai perhitungan awal dalam merancang alat/mesin. Jenis bahan dasar pipa adalah baja karbon rendah (low carbon steel) dengan unsur karbonnya sekitar $<0,3 \%$. Modulus elastisitas baja $(E)$ adalah 190-210 Gpa, Modulus elastisitas geser $(G)$ adalah 75-80 Gpa, dan poisson's rasio adalah 0,27-0,30.

- Momen Inersia (I) pada pipa

$$
\begin{aligned}
I & =\frac{\pi}{64}\left(D^{4}-d^{4}\right) \\
& =\frac{3.14}{64}\left(3.4^{4}-3.18^{4}\right) \\
& =0,049\left(1336.33 \mathrm{~cm}^{4}-102.26 \mathrm{~cm}^{4}\right) \\
& =60.45 \mathrm{~cm}^{4}
\end{aligned}
$$


- Dalam membengkokan pipa sebesar $34 \mathrm{~mm}$ dengan panjang $2136 \mathrm{~mm}$ dan radius minimum $340 \mathrm{~mm}$. Diketahui modulus elastisitas $(E): 207$ $\mathrm{Gpa}=30 \mathrm{Mpsi}=210000 \mathrm{~kg} / \mathrm{cm}^{3}$, maka membutuhkan gaya sebesar: $143.80 \approx 145 \mathrm{~kg}$

- Torsi pada roller

Untuk menghitung besarnya torsi pada roller maka terlebih daluhu mengetahui gaya gesek antara roller dengan pipa (baja dengan baja). Diketahui besarnya gaya $(F)$ pada pipa $72.5 \mathrm{~kg}$, maka besarnya torsi pada roller adalah:2.25 kgm $=22.10 \mathrm{Nm}$

\section{Perancangan Sistem Transmisi}

Sistem transmisi alat/mesin yang digunakan terdiri dari beberapa komponen yaitu speed reducer, kopel, rantai. Pada speed reducer tersebut diharapkan mampu menghasilkan reduksi putaran motor yang memenuhi syarat rencana kapasitas kerja dan memenuhi standart keamanan bagi operator. Sistem speed reducer dipilih karena kemampuan untuk mereduksi putaran sangat tinggi dan konstruksi yang sederhana. Sistem speed reducer ini sudah terpasang baik didalam head stock pada mesin bubut yang diteruskan dengan roda gigi untuk mengatur putaran mesin yang akan digunakan. Perawatan juga sangat terjangkau dengan memberi pelumasan pada roda gigi secara berkala untuk umur yang lebih panjang. Putaran yang dihasilkan dari mesin bubut bervariasi bisa digunakan sesuai kebutuhan.

\section{Perhitungan Poros dan Pasak}

Poros merupakan komponen yang sangat penting didalam pembuatan alat/mesin pengerol pipa. Untuk itu dibutuhkan alur perhitungan yang baik untuk membuat poros. Data yang diketahui dalam perhitungan poros adalah :

$\begin{array}{ll}\text { Daya yang } & : 1 \mathrm{HP} \text { atau } 746 \text { watt } \\ \text { ditransmisikan } & \\ \text { Putaran poros } & : 15 \mathrm{rpm}\end{array}$

Faktor koreksi (Fc) : 1.2 (untuk daya normal)

\section{Perhitungan Bearing}

Untuk mengetahui beban maksimal yang diterima pada bearing dapat dicari dengan menggunakan persamaan (2).

Keterangan :

$$
\begin{aligned}
P_{\mathrm{o}} & =\frac{P}{Z_{t} \times \cos \beta} \\
& =\frac{36.25}{12 \times \cos 90^{\circ}} \\
& =36.25 \mathrm{~kg} \\
& =355.61 \mathrm{~N}
\end{aligned}
$$

$P_{o}$ : beban maksimal pada bearing (kgt)

$P$ : beban pada bearing (kgf)

$Z_{t}$ : jumlah rolling body bearing

$\beta$ : sudut pembeban

\section{Proses Fabrikasi dan Perakitan}

Tahap fabrikasi dan perakitan merupakan rangkaian pekerjaan dari beberapa komponen material yang akan dirangkai menjadi satu dengan pelaksanaan setahap demi setahap sampai menjadi suatu bentuk salah satu konstruksi sehingga dapat dipasang atau dirakit menjadi sebuah bentuk akhir yang diinginkan dan direncanakan sebelumnya. Pelaksanaan akan dilakukan dengan beberapa tahap yang akan dijelaskan dan disertakan tampilan gambar gambar saat proses fabrikasi dan perakitan berjalan. Gambar 4 adalah alat/mesin yang sudah dirakit selesai dilakukan pengecatan.

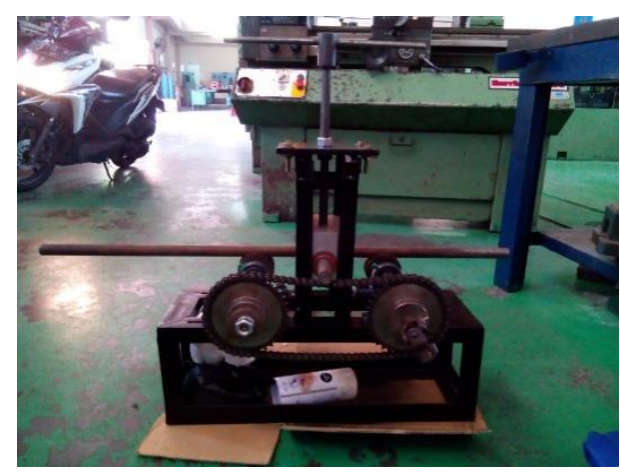

Gambar 4. Perakitan Mesin

\section{Hasil dan uji coba}

Setelah melaui proses pengecatan dan perakitan semua mesin telah terpasang seperti perakitan mesin yang akan dilakukan pengujian.

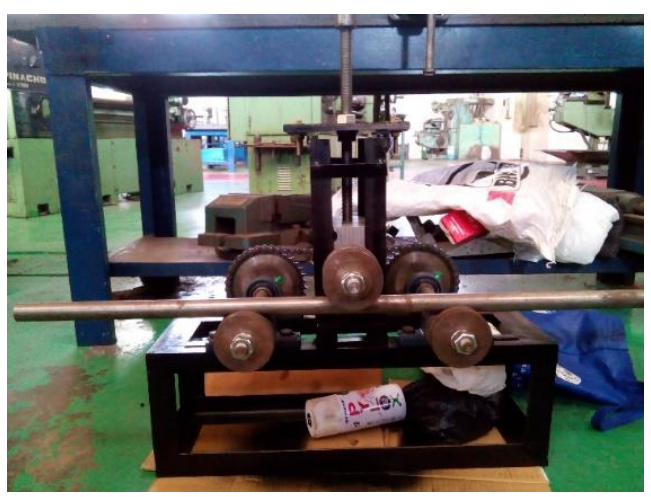

Gambar 5 :mesin tampak depan

Dilakukan pengujian pengerolan secara bertahap tahap dihasilkan hasil setelah pengerolan.

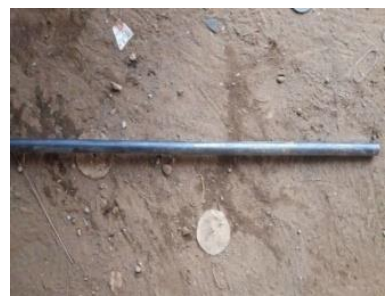

(a)

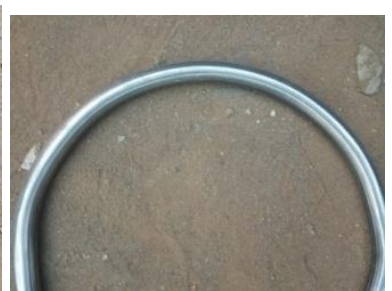

(b)
Gambar 6. (a) awal material, (b) setelah di roll 


\section{PENUTUP}

Pembuatan desain dan gambar kerja mesin roll bending portable ini dikerjakan menggunakan software Autodesk Autocad 2007. Gambar kerja mesin roll bending portale terdiri dari : gambar kerja rangka dan bagian-bagiannya, gambar kerja pengelasan, gambar kerja slide dan bagianbagiannya, gambar kerja poros geser dan poros tetap, gambar kerja matras roll.

Mesin roll bending portable ini memiliki spesifikasi sebagai berikut :

Dimensi : $350 \times 250 \times 560 \mathrm{~mm}$

Penggerak utama : Mesin bubut dibantu dengan cross joint

Mekanisme : Tuas ulir linier

penekan

Sistem transmisi : Gear box reduser 1:60, 2 buah gear sprocketrs 40 (36:36), rantai rs 40

Dari hasil uji coba mesin didapatkan hasil proses pengerolan sebagai berikut: pada pipa galvanis diameter 1 inch dengan panjang mulamula 580mm dengan hasil radius $195 \mathrm{~mm}$ dengan waktu 20 menit; dan pada pipa galvanis diameter 1 inch dengan panjang mula-mula $1200 \mathrm{~mm}$ dengan hasil radius $980 \mathrm{~mm}$ dengan waktu 30 menit.

\section{DAFTAR PUSTAKA}

Fauzan. (2010). Roll bending pipa untuk pembuatan rangka canopy. Surabaya: Institut Teknologi Sepuluh Nopember.

Mustaqim, A. (2012). Perancangan Alat Pengerol Pipa. Yogyakarta: Universitas Negeri Yogyakarta.

Novandra, D. R., Tiyasmihadi, T., \& Hamzah, F. (2018). Rancang Bangun Roll Bending Machine With Hydraulic Assist. In Conference on Design and Manufacture and Its Aplication (Vol. 1, pp. 168-174).

Popov, E. P. (1996). Mekanika Teknik. Jakarta: Erlangga.

ROHIM, M. C., \& Yunus. (2015). RANCANG BANGUN MESIN PENGEROL PLAT BERGELOMBANG. Jurnal Rekayasa Mesin, 2(02).

Sularso, \& Suga, K. (2008). Dasar Perencanaan dan Pemilihan Elemen Mesin (Cetakan ke). Jakarta: PT Pradnya Paramita.

Takeshi, S. G., \& Sugiarto, H. N. (1999). Menggambar Mesin Menurut Standar ISO. Jakarta: PT. Pradnya Paramita. 
YE Nurcahyo, dkk / Teknika : Engineering and Sains Journal, Vol. 2, No. 2, Desember 2018, 109-114

Halaman ini sengaja dikosongkan 